BIO Web of Conferences 1, 00089 (2011)

DOI: $10.1051 /$ bioconf $/ 20110100089$

(C) Owned by the authors, published by EDP Sciences, 2011

\title{
Escaping Dante's hell with an informed virtual environment for interactive bodies in movement
}

\author{
Indira Thouvenin, Francis Rousseaux \\ (*)UMR CNRS Heudiasyc, France \\ (*) URCA/CReSTIC, France \\ E-mail: indira.thouvenin@utc,francis.rousseaux@univ-reims.fr
}

\begin{abstract}
The paper addresses the question of Informed Virtual Environments from the point of view of some philosophical and ethical key-issues. By browsing some eclectic experiences like dancing, serving Asturian cider, trying to escape Dante's Hell or manufacturing a tyre, important questions are raised, and some answers are sketched about some possible ways of designing our future environments: but gestures have then to be considered as cultural objects too, being not reducible to their physical traces.
\end{abstract}

\section{Introduction}

Dance is traditionally interested in showing to a certain public choreography of interactive bodies in movement. But if we enlarge that definition toward other purposes like 'manufacturing a complex object together operators and machines'[1], many operations in manufacturing could be in some way considered as dancing interactive choreographies.

The question is now to put forward a notation/annotation framework that could efficiently handle the human-machine co-operation, until providing a satisfying environment for training, learning, and developing creativity... from both sides. Many worldwide scientific contributions are currently proposing such exploratory environments, but there is also a need for some philosophical and ethical exchange about what appears as an essential issue for the future of Virtual Reality.

\section{Work as a dance}

When an operator manufactures a tyre (Fig. 1) using a sophisticated, noisy, huge and costly machine, he/she interprets a true choreography where the constraints are the space between tools and himself, the very minutely controlled time of manufacturing [10], and the accuracy of technical gestures. The rhythm is given by manufacturing steps [7] and sequences that succeed in any step without falling off, while organising a few breathing moments corresponding to the movements to be carried out for a sufficiently flexible and efficient execution. The person is thus led to express him/herself within this sphere, both technical and resonant, defined by the objects to be handled. His/her gesture must free him/her from any long-term discomfort: the ergonomics of his workstation is designed like a theatre stage where actors are allowed to go to and fro.

\section{At hell's gate, coffee is served cold}

When we put forward this metaphor of the technical gesture as dance, the question of the level of freedom left to the operator between digitalised meeting points appears striking, deploying a potentially infernal field of action. It is difficult here not to think of Dante's Hell [1], together with its subtle critique due to Gombrowicz.

First, let us read again the famous Florentine...

"Through me the way is to the city dolent;

This is an Open Access article distributed under the terms of the Creative Commons Attribution-Noncommercial License 3.0, which permits unrestricted use, distribution, and reproduction in any noncommercial medium, provided the original work is properly cited. 
Through me the way is to eternal dole; Through me the way among the people lost.

Justice incited my sublime Creator; Created me divine Omnipotence, The highest Wisdom and the primal Love.

Before me there were no created things, Only etern, and I eternal last, All hope abandon, ye who enter in!"

The Divine Comedy, Alighieri Dante[1], Canto III

For Dante, the damned can only moan with the agonies of remorse. At the occasion of the rare visits of a mortal, as in the case of Dante accompanied by Virgil, he can only witness of the perpetual drama felt in his flesh. In a mysterious way, hope seems to have definitively abandoned him, following Dante's inscription on Hell's gate.

Now, let us listen to Gombrowicz [2]. In his opinion, the Devil's realm is too serious in Dante's Hell to embody the metaphysical Evil, necessary for modernising the medieval theodicy. This demon is too (deterministically) perfect, and the cycle of eternal suffering followed by compulsive sorrow, although in conformity with our experience of the imperative nature of pain, leaves him without any transcendental role.

A hidden intuition urges Gombrowicz to suggest the complexification of Dante's infernal structure : as such, it is likely to appear too flat, simple, boring (repetitive and iterative) to guarantee the "pensée unique" of the damned.

In Hell as seen by Gombrowicz, the fault must rule in the Abyss, and hierarchical order must to leave place to a disconcerting recursion. And if by chance, some coffee had to be served ... it would be cold. So, Gombrowicz comes to think that the best way of preventing the unexpected return of hope in the very bosom of Hell is still to disturb perpetually the conditions where radical seclusion is made possible, by opening traps. The torturer soon learns how to add vice into the torture he inflicts, by giving it through unforeseeable modes of cruelty.

"Through me the way is to the deepest City, eternity which carries on its Fall; through me the way is to eternal Evil a self-infected, rotten and debased thing, through me the way among the people lost, an everlasting race ..."

About Dante, Witold Gombrowicz [2], pages 145 and 146
This thesis seems to be only able to redefine the formal modalities of Hell, without unveiling its essence. But it prepares the theoretical possibility of an immanence within the transcendence: something is acting from within the structure, there is an acting nothingness, like an immanent grace in Marxist theory, or an historicism claiming that there is a radical exteriority in history, and not only the same which improves itself (progress) or a nihilism beyond history's end. There can be a form of mutant human subjectivity, between changes of degree and changes of nature.

What are the conditions making possible this subjectivity created through mutation? How could one think about it? This is a typical Gombrowicz' meditation when he transforms memory as a storage of recollection acts into the question of a changing relationship with respect to such acts.

"To share things with the past, is to elaborate, painfully and restlessly, to recall it continuously to come back into existence... But, as we "read" this past thanks to tracks it left for us, and since these depend on hazard, even on the matter more or less crumbly, and so reliant on various accidents occurred in time - which bring these tracks until us, then this past can be only chaotic, accidental, fragmentary ... (...). The past is therefore a scenario made of snatches ... here is its nature ... Nevertheless, this urges us to new reflexion, this desire we have at our disposal, against any adversity, a complete and living past, full of characters, quite concrete, and this need must be well rooted into us ..."

About Dante, Witold Gombrowicz, pages 147 and 148

Digital technologies allow us to continue the transformation inaugurated by Gombrowicz, and to frustrate the pretension of the analogous technique to achieve a complete description. Nothing was never said on what happens between two digitalised samples, between two compulsory passing points of the gesture.

\section{Dancer-operator versus machine choreographies}

In fact, human gesture representation in the virtual world can bring a glimmer of hope in this descent to Hell: the training simulator for technical gesture (like the one built by UTC for the Continental company [4], that could be qualified as a Serious Game), allows us to understand not only the perfect machine's mechanical functioning, but also man-machine interactions. This interactive visualisation, such as a video game, 
alleviates the operator's cognitive effort by giving him very clear signals concerning the states of opening, breathing and freedom. Precise constraints to which he has to submit become supports and markers, and a more flexible and truthful gesture can be imagined.

Such a change gives birth to a new point of view: dancing becomes alive and singular, it is nurtured on each body, each material transformation, each rapid or heavy step, each humble but beautiful operation, each concentrated or worried glances, each beginner's anxiety, or each nonchalance of those bestowed with a knowing body ... Of the deep evening weariness, of the morning coolness, and of the machine's noisy and powerful response.

As in a monstrously unbalanced hand to hand struggle, the dancer-operator fights with his/her hands, torso, feet, faced to the enormous automaton, faced with the monster's steel jaws, and has to rely on his/her knowledge of space, his/her own body's perception in the machine's empty interiority, his/her intimate knowledge of the choreography he interprets together with the machine.

Which trace of this choreography could we inscribe into the digital world? The main traces habitually used for this choreography of the operative mode are descriptions through schemas, films, synthetic image animations based on the man-machine chart.

The choreographer's notation [5] could be translated into this framework of the technical gesture and would include only the memorisation of invariants and essential parts of the human gesture and machine's movement, while offering the possibility of living afterwards this gesture by perceiving it from inside. This notation could both serve as a trace, and support a new situation: that of the game between the man who learns to dance and the system which operates the records[6].

The gesture annotating capitalised in a knowledge base, and their lecture following different points of view, without the constraints of repetition or ordered reading, could bring a scent of paradise by giving us a new degree of freedom: the perfect gesture is no longer seen as an inaccessible and confuse model, but as a clear and readable framework [7], where the danceroperator can improvise.

\section{The dancer of Gijon}

One thinks without fail to Charlie Chaplin's Modern Times, but also to the sportsman repeating a complex dynamic chaining, or yet to the pianist studying a virtuoso passage. It immediately appears that the categorisation of our activities relays pose traditionally on their exogenous destination and productivity much more than on the endogenous aptitudes they mobilise are experienced by the operator from the inside.

Undoubtedly, that is the reason for which one distinguishes habitually between dancing and other body activities, the former claiming to let see the bodies animated for themselves, in a choreography offered to the reception and interpretation without any other aim: the choreographic movement is not referenced to respect to an external target, but is given as such, folded in an immanent meaning.

It is obvious that the distinction is coarse and largely artificial: because choreography always evokes finalised gestures, and dancers repeating a choreography address the public spectacle as a target. And, finally, because finalised gestures can be seen and appreciated by themselves, as if they were danced.

Not so long ago, we astonished an Asturian waiter serving cider by suggesting that he should become an air-traffic controller: we must admit that our waiter was truly extraordinary, with a stupefying dexterity and organisation (Fig. 3). Of course, servers are always remarkable in the sidreries of Gijón ${ }^{1}$. But that one, already quite visible because of being tall and slender ${ }^{2}$, was deploying so efficient an organisation that our glance was captured. He had disposed several large pedestal tables at the strategic places of the restaurant's room, on which he had grouped together the sidra asturiana bottles for the neighbouring tables, and moved very fast among them while serving culin after culin, without any doubt on the bottle's owner. Once you know that cider bottles are smaller in the Asturias than in the remainder of Spain and that the average consumption is generally high (often 3 bottles per person/meal), one can but calculate the number of empty bottles on the pedestal tables after a friendly meal; moreover, the traditional bill is established on the basis of the dead bottles left on the battle field...

\footnotetext{
1 The sidra is poured as un culin o culete from a height into a wide glass, with the arm holding the bottle extended upwards and the one holding the glass extended downwards; this technique is called to estanciar and is done to get air bubble into the drink. Then the customer is given the fine-brimmed glass containing a very small quantity of a cider as coarse as possible, but in fact unforgettable. The sidra is drunk d'un tragu and the glass is passed to a neighbour.

2 In the Asturian sidreríes (Northern Spain), customers are rather short and fat, irresistibly attracted by the marvellous mountains of tapas offered by the owner and exposed just under their nose : tapas de tortilla, de jamón, de pesca or de marisco.
} 


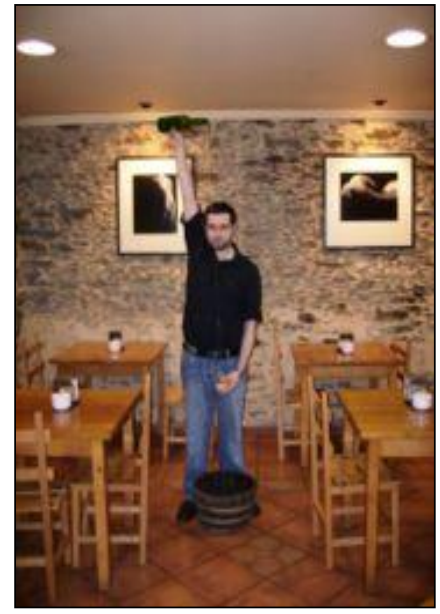

Figure 3: Typical gesture of an Asturian waiter serving cider

Why should one only foresee a brilliant career in catering for this waiter, betting that a chief will not be long in remarking him in view of a promotion? The aptitudes manifested by our waiter could be compared with those of air-traffic controllers, i.e. the capability to quickly discern objects on which an identical technical procedure is applied ...

Here is the kernel of the question. The operator's gestures are idealised/stylised/topicalised/categorised in order to build up models, afterwards an avatar complying with these models is shown, hoping that the operator will identify himself with the moving avatar. If the device appears to be satisfactory, the reason is that the operator, identifying himself with every force of the moving avatar, believes incidentally that the idealisation/stylisation/topicalisation/ categorisation of his gestures/actions is the appropriate one, and therefore he is a good worker in the social sense of the term.

As is often the case, a major part of the interesting questions is masked during a fast interpretation, the experience functions, but due to other, unexpected reasons.

\section{Annotating as gesture re cording/archiving}

This capacity of the Gijón dancer to get his bearings in space and time is very interesting, in particular when we try to inscribe digitally this gesture in a virtual world.

Like a photography modifying the reasons of painting, the digital trace produced in virtual reality modifies the recording modes. Two questions come to mind:
- how could we write [8] the gesture avoiding the complete storage of what an avatar can do in the simulator?

- how could we re-read it by choosing well identified parts?

In both cases, it is necessary to view the digital inscription of the gesture as a gesture annotating allowing us to memorise, classify and explore a track in order to re-run a dance, at wish and interactively.

This work on the annotating [9] is still incipient because it requires to understand, on the one side, the flesh, the body warmth, the movement of the living being, the dancer's breathing, and on the other the coldness of the digital system, the accuracy in time and space of the 4D modelling (time being the $4^{\text {th }}$ dimension), the classification of the different forms of gestures, the inscription and the digital description.

This description makes us think of a well drawn image of a house which « calls easily to our desire to dwell in », as Bachelard [10] said:

\begin{abstract}
"Our chimera, which urges us to live in some places, is sometimes caused, here again, by the grace of a simple drawing. But in this case, the grace of a curve is not a simple Bergson's movement with well placed inflexions. It is not only a deploying time. It is also a dwelling space constituted harmoniously... Here we at a minimum de refuge, in the ultra-simplified schema of a rest daydreaming. Only the dreamer who incurves himself to contemplate these loops knows the joy of the drawn rest."
\end{abstract}

This drawn rest is in our case that of a security brought by a clear representation of the gesture when the operator-dancer understands rapidly and efficiently his role. Hope can be a motor only if a space of accomplished promises exists, the insertion in space and time is solid, and movement can be based on stone-like ground. The matter is not to recognise oneself in the moving avatar, but to base oneself on a proper gesture language in order to reach these breathing points authorised in the rigidity of the representation.

In comparison, Hell is truly the deceived hope, the imprecision, the lack of visibility on possible future, the absence of leading marks in space and time, that is the Hell of uncertainty.

Only a mixture of desire and renunciation can give birth again to a gesture language relying on ancient and fertile traces, as expresses Georges Didi Huberman [11]:

"Air and stone meet each other in the image because, in many pregnant images, one finds a 
mixture of superlative grace and immense sorrow, performed gestures and suspended gestures, desire and renunciation, nearconsolation and inconsolable loss."

\section{Conclusion and discussion}

By considering technical gestures as embodied physical movements, we surely approach some very useful low-level descriptions of it. But we cannot get the abstract truth of gesture by attempting to reduce it to some, even fine, combination of those low-level descriptors.

High-level descriptors of technical gestures can elsewhere be provided by considering them like virtual pieces of performing art to be directed.

Trying to match those two description levels, by maintaining some philosophical and ethical scientific discussion, is probably a powerful perspective for turning our Informed Virtual Environments into creative workshops. But such a research project cannot be settled without admitting that technical gestures can never be simply repeated: they singularise themselves, they change/mutate by being directed again, they adapt to become more and more concrete/accurate/efficient, as explained by Gilles Deleuze and Gilbert Simondon. This has considerable impact on future indexing/archiving/annotating strategies of technical gestures, considered as virtual pieces of performance art.

\section{References}

[1] Dante A., La Divina Commedia: Inferno, Florence, written in 1314

[2] Gombrowicz W., Sur Dante, in "Contre les poètes", pages 141 to 167, written at Vence en 1966 for Kultura, Journal III, Complexe, 1988

[3] Olive, J. and Mouttapa Thouvenin, I., Virtual tyre production: learning industrial process through an informed virtual environment, IEEE International Conference on Multimedia and Expo, Barcelone, Spain, 2011.

[4] Continental simule la production, section La vie des usines, L'usine nouvelle, 22 février 2007, N³044

[5] Laban R., Ullmann L., The Mastery of Movement, Plays, Inc.

[6] Olive J., Thouvenin I., Lemasson G., Sbaouni M., Tire Manufacturing supported by virtual environment, Proceedings of Laval Virtual 2006, pp.159-163, Laval France, April 2006

[7] Luciani A., Evrard M., Couroussé D., Castagné N., Cadoz C., Florens J-L., A basic gesture and motion format for virtual reality multisensory, in the Proceedings of the 1st international GRAPP Conference on Computer Graphics Theory and Applications, ISBN: 972-8865-39-2, Setubal Portugal, March 2006

[8] Sutton V., Sutton Movement Shorthand; Writing Tool For Research, National Symposium on Sign Language Research \& Teaching, Chicago, Illinois USA, 1977

[9] Lenne, D. and Thouvenin, I. and Aubry, S., Supporting Design with 3D-Annotations in a Collaborative Virtual Environment, Research in Engineering Design vol. 20 num. : 3 pp. 149-155 (september 2009)

[10] Bachelard G., La poétique de l'espace, Quadrige, PUF, 1957

[11] Didi Huberman G., Gestes d'air et de pierre, corps, parole, souffle, image, Paradoxe, Les éditions de minuit, 2005 